\title{
REVIEW \\ Applications of Peridynamics in Marine Structures
}

\section{Erkan Oterkus*}

PeriDynamics Research Centre, Department of Naval Architecture, Ocean and Marine Engineering, University of Strathclyde, Glasgow, United Kingdom

\section{ARTICLE INFO}

Article history

Received: 30 December 2021

Accepted: 31 December 2021

Published Online: 10 January 2022

Marine environment is a harsh and challenging environment for both operators and analysers due to extreme weather conditions. As a result of these conditions, marine structures are subjected to extreme and/or cyclic loadings. This will then lead to various different damage modes including corrosion and fatigue. Such damage modes are major threats to the reliability and integrity of marine structures which can cause risk on human and environmental safety, and yield financial losses. Moreover, climate change is a major concern which requires urgent attention. In order to minimize the negative effects of climate change, energy transition from utilisation of fossil fuels to greener energy solutions, such as offshore wind, should be adapted. There is currently a rapid progress on investment on green technologies especially offshore wind energy generation. Another emerging area is hydrogen which is considered as the environmentally friendly fuel of the future.

There are various ways to produce hydrogen which are classified as grey, blue and green hydrogen production. Since $\mathrm{CO}_{2}$ is also produced as part of the grey and blue hydrogen production, green hydrogen becomes the most environmentally friendly option. To produce green hydrogen, energy produced by offshore wind turbines can be utilised. A potential challenge of this approach is how to transport hydrogen to onshore. Utilisation of offshore pipelines can be an economical option. In addition, if there is already an existing infrastructure available for oil \& gas applications, this can be even much preferable option without any need to install a new pipeline system. However, this requires extra care since these pipelines were not originally designed to transport hydrogen.

\footnotetext{
*Corresponding Author:

Erkan Oterkus,

PeriDynamics Research Centre, Department of Naval Architecture, Ocean and Marine Engineering, University of Strathclyde, Glasgow, United Kingdom;

Email: erkan.oterkus@strath.ac.uk
}

DOI: http://dx.doi.org/10.36956/sms.v4i1.475

Copyright (C) 2022 by the author(s). Published by Nan Yang Academy of Sciences Pte Ltd. This is an open access article under the Creative Commons Attribution-NonCommercial 4.0 International (CC BY-NC 4.0) License. (https://creativecommons.org/licenses/ by-nc/4.0/). 
Hydrogen can cause embrittlement problem, known as hydrogen embrittlement, especially for metallic structures and can cause cracking for loads much smaller than the design loads.

In order to minimize all the risks associated with the harsh marine environment and energy transition process, advanced computational methodologies should be utilised such as peridynamics as part of the analysis process. Peridynamics ${ }^{[1-4]}$ is a new computational methodology which is especially suitable for failure analysis of materials and structures. Peridynamic equations are in the form of integro-differential equations and do not contain any spatial derivatives. Therefore, these equations are always valid regardless of discontinuities such as cracks. Definition of failure is pretty straightforward, and it is possible to analyse any number of cracks since cracks are not treated as special objects.

There are many application areas for peridynamics to be utilised in maritime field. One potential area is to use peridynamics for the analysis of ice-structure interactions ${ }^{[5-8]}$. There is currently an interest to use Northern Sea Route to ship products from Far East to Europe since this route is much shorter than the current route. However, icestructure interaction is a major concern since ships should be designed by considering potential impact of ice pieces on ship hull which can cause significant damage to the ship hull as in the Titanic accident in the past.

Another important application of peridynamics is modelling the influence of underwater explosions on submarines or naval vessels. If an underwater explosion takes place, a shock wave is generated and this can cause significant damage to the structure. Predicting damage due to shock loading, especially if the structure is made from composite material, is challenging. Although composite materials have several advantages with respect to traditional metals, their failure behaviour is complex since different damage scenarios can occur including fibre breakage, matrix cracking, fibre-matrix splitting and delamination. Peridynamics is capable of accurately predicting these failure modes in structures subjected to different loading conditions including shock loading ${ }^{[9-11]}$.

Another important application of peridynamics in marine structures is corrosion damage modelling. There are different corrosion mechanisms which can occur in structures due to material type, environment, and loading. One of the common corrosion damage mechanisms is pitting corrosion which creates localised damage in the structures. Pitting corrosion damage areas can act as stress raisers and cracks can initiate and propagate from these locations. From modelling point of view, this requires multiphysics and multiscale analyses to simulate coupled diffusion and mechanical fields by considering the microstructure which can be done in a single peridynamic framework ${ }^{[12,13]}$. Moreover, peridynamics can also simulate hydrogen embrittlement phenomenon as a stress corrosion cracking mechanism ${ }^{[14]}$.

Fatigue is also an important damage mode in marine structures. S-N curve and Paris Law are common approaches which are utilised for fatigue analysis of marine structures. Fatigue damage is a complex process with three phases including fatigue initiation, fatigue crack propagation and final failure. S-N curve is capable to represent fatigue initiation and can provide fatigue life. However, it cannot predict how the fatigue damage evolves. Paris Law approach can predict how a fatigue crack can grow. However, it is not capable to predict fatigue initiation and final failure phases. As an alternative approach, peridynamics is capable of representing all three phases of fatigue damage ${ }^{[15-18]}$ and can serve as a less conservative tool for the design and analysis of marine structures.

Finally, peridynamics can also be used for failure analysis of energy storage devices such as marine batteries ${ }^{[19]}$ and fuel cells ${ }^{[20]}$. Such devices will serve an important role to reduce carbon emissions in future ships and make significant contributions to reach net zero targets. As a final note, peridynamics, as a new and emerging computational methodology, can be a suitable and alternative computational tool for failure analysis of problems relevant to marine structures applications.

\section{References}

[1] Silling, S.A., 2000. Reformulation of elasticity theory for discontinuities and long-range forces. Journal of the Mechanics and Physics of Solids. 48(1), 175209.

[2] Silling, S.A., Askari, E., 2005. A meshfree method based on the peridynamic model of solid mechanics. Computers \& structures. 83(17-18), 1526-1535.

[3] Silling, S.A., Epton, M., Weckner, O., Xu, J., Askari, E., 2007. Peridynamic states and constitutive modeling. Journal of Elasticity. 88(2), 151-184.

[4] Madenci, E., Oterkus, E., 2014. Peridynamic Theory and Its Applications. Springer, New York, NY.

[5] Vazic, B., Oterkus, E., Oterkus, S., 2020. In-plane and out-of plane failure of an ice sheet using peridynamics. Journal of Mechanics. 36(2), 265-271.

[6] Lu, W., Li, M., Vazic, B., Oterkus, S., Oterkus, E., Wang, Q., 2020. Peridynamic modelling of fracture in polycrystalline ice. Journal of Mechanics. 36(2), 223-234.

[7] Vazic, B., Oterkus, E., Oterkus, S., 2020. Peridynam- 
ic model for a Mindlin plate resting on a Winkler elastic foundation. Journal of Peridynamics and Nonlocal Modeling. pp. 1-10.

[8] Liu, M., Wang, Q., Lu, W., 2017. Peridynamic simulation of brittle-ice crushed by a vertical structure. International Journal of Naval Architecture and Ocean Engineering. 9(2), 209-218.

[9] Diyaroglu, C., Oterkus, E., Madenci, E., Rabczuk, T., Siddiq, A., 2016. Peridynamic modeling of composite laminates under explosive loading. Composite Structures. 144, 14-23.

[10] Oterkus, E., Madenci, E., 2012. Peridynamic analysis of fiber-reinforced composite materials. Journal of Mechanics of Materials and Structures. 7(1), 45-84.

[11] Kilic, B., Agwai, A., Madenci, E., 2009. Peridynamic theory for progressive damage prediction in center-cracked composite laminates. Composite Structures. 90(2), 141-151.

[12] De Meo, D., Oterkus, E., 2017. Finite element implementation of a peridynamic pitting corrosion damage model. Ocean Engineering. 135, 76-83.

[13] De Meo, D., Russo, L., Oterkus, E., 2017. Modeling of the onset, propagation, and interaction of multiple cracks generated from corrosion pits by using peridynamics. Journal of Engineering Materials and Tech- nology. 139(4), 041001.

[14] De Meo, D., Diyaroglu, C., Zhu, N., Oterkus, E., Siddiq, M.A., 2016. Modelling of stress-corrosion cracking by using peridynamics. International Journal of Hydrogen Energy. 41(15), 6593-6609.

[15] Silling, S.A., Askari, A., 2014. Peridynamic model for fatigue cracking. SAND2014-18590. Albuquerque: Sandia National Laboratories.

[16] Hong, K., Oterkus, S., Oterkus, E., 2021. Peridynamic analysis of fatigue crack growth in fillet welded joints. Ocean Engineering. 235, 109348.

[17] Nguyen, C.T., Oterkus, S., Oterkus, E., 2021. An energy-based peridynamic model for fatigue cracking. Engineering Fracture Mechanics. 241, 107373.

[18] Zhu, N., Kochan, C., Oterkus, E., Oterkus, S., 2021. Fatigue analysis of polycrystalline materials using Peridynamic Theory with a novel crack tip detection algorithm. Ocean Engineering. 222, 108572.

[19] Wang, H., Oterkus, E., Oterkus, S., 2018. Peridynamic modelling of fracture in marine lithium-ion batteries. Ocean Engineering. 151, 257-267.

[20] Wang, H., Oterkus, E., Celik, S., Toros, S., 2017. Thermomechanical analysis of porous solid oxide fuel cell by using peridynamics. AIMS Energy. 5(4), 585-600. 